\title{
A aventura sociológica de Florestan Fernandes
}

\author{
MARIA ARMINDA DO NASCIMENTO ARRUDA ${ }^{I}$
}

\author{
“A veracidade do saber é determinada numa situação prática." \\ (Pensamento de Karl Marx citado por Florestan Fernandes em entrevista)
}

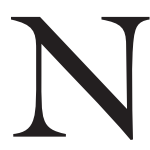
Ão É DE SURPREENDER a existência de vasta fortuna crítica a respeito da trajetória e da obra de Florestan Fernandes (1920-1995); tampouco o volume de intérpretes que se debruçaram sobre os mais diversos ângulos do seu legado, bem como o aparecimento de novas gerações de pesquisadores dedicados a analisar a sua produção sociológica. As interpretações compreendem um arco de estudos que problematiza o caráter singular do seu pensamento, acentuando seja a densa contribuição analítica da sua reflexão, seja a originalidade da sua interpretação sobre a constituição da sociedade moderna no Brasil, seja, ainda, a sua capacidade de explicar as iniquidades persistentes da nossa sociedade, vertente que, comumente, ressalta a dimensão política e engajada da sua obra, à qual se agrega o tratamento da sua condição de intelectual público, frequentemente associada à sua biografia.

As análises sobre a aventura sociológica de Florestan Fernandes multiplicaram-se e adensaram-se no presente, fenômeno que ultrapassa as celebrações dos cem anos do seu nascimento, atestado por ampla bibliografia e que não cabe explorá-la nessa ocasião. ${ }^{1}$ Motivos distintos podem ser atribuídos ao crescimento do interesse pelos seus trabalhos. Em publicação recente, chamei a atenção para o fato de a alentada e diversificada fortuna crítica a respeito das diversas dimensões da sua trajetória emanarem, como sói acontecer, de perguntas derivadas do tempo presente (Arruda, 2018, p.47-8). Em outro texto, sublinhei que, embora não de forma exclusiva, as diferentes leituras tendem a acentuar o caráter militante da sua sociologia, vertente especialmente destacada em contextos de afirmação de tendências políticas ou de disputas incertas, de arrefecimento das bandeiras progressistas e de perda de legitimidade das causas democráticas. “Naturalmente, há uma pletora de razões a explicar essas análises, manifestas no caráter incomum da sua biografia e no carisma que o acompanhou especialmente nas décadas anteriores ao seu falecimento, bem como na sua resistência firme e intolerante a todas as formas de desigualdade e de contextos antidemocráticos" (Arruda, 2020, p.109). 
Interessante perceber que a dimensão identificada com o traço militante, isto é, do intelectual público e politicamente engajado, socialista e devotado às causas do que denominou de "os de baixo", embora apareça, muitas vezes, como a forma mais difundida das interpretações, nunca obscureceu os estudos que pensaram a sua contribuição no crivo da envergadura analítica e da contribuição indelével ao entendimento do processo de modernização no Brasil - e que renovou as concepções das transformações em curso - sem, contudo, diminuir o escopo crítico das suas análises (Martins, 1996; Martins, 1998; Cohn, 1987; Cohn, 1999; Cohn, 2020; Arruda, 2003, 2015; Bastos; Botelho, 2010; Jackson; Blanco, 2014; Botelho; Brasil Jr., 2020). Nesse cenário,

[...] penso que as suas posições críticas resultam do modo como o sociólogo construiu o seu problema analítico, da demarcação de um lugar inusual para interpretar a sociedade brasileira, qual seja o das camadas populares e aqueles que foram deserdados da modernização, presentes nos seus estudos sobre índios, negros, classes subalternas e trabalhadores. Em suma, creio que a dimensão radical de Florestan não se apreende satisfatoriamente, quando se tem como ponto de partida e de chegada a denominada sociologia militante, mas antes quando se pode revelar por via da pesquisa $\mathrm{e}$ interpretação que a sua crítica é parte da estrutura interna da obra. (Arruda, 2020, p.109)

Reside aí, possivelmente, não apenas a originalidade e a força do seu pensamento, capaz de elucidar as dimensões críticas das suas reflexões e os desdobramentos políticos da sua obra, que levam à afirmação do papel público dos intelectuais, sem empalidecer, todavia, a envergadura analítica dos seus trabalhos.

Florestan Fernandes foi distinto, de fato, dos denominados intérpretes modernos do Brasil, que trataram do problema da formação da sociedade brasileira, paradigma que criou toda uma linhagem intelectual, de cuja tradição o próprio sociólogo não está distante, embora participe de modo oblíquo e singular (Arruda, 2017). Inclusive, por isso, distingue-se dessa marcante tradição intelectual que tratou da formação do Brasil como país, como nação, como cultura. Em termos explícitos, teoria e objeto de investigação estão mutuamente referidos na sua obra e se mesclam na construção do problema analítico, cuja relação caracteriza a linguagem sociológica especializada. Em entrevista recentemente republicada afirmou: "a especialização é necessária, ninguém vai combater a especialização, nem uma terminologia precisa, porque o uso de uma terminologia precisa é um requisito do conhecimento científico" (Fernandes, 2020, p.76).

Nesse cenário, entende-se por que os problemas formulados por Florestan Fernandes são lidos na chave da atualidade, particularmente no presente, quando as desigualdades sociais se agudizaram no mundo, desde 1980, e adquiriram inescapáveis contornos políticos (Piketty, 2014; 2015; Boushey et al., 2017); os regimes democráticos refluíram; as variadas manifestações de discriminação retornaram com profundidade surpreendente, intensificadas nesses tempos de 
pandemia, que tiveram o condão de escancarar todas as iniquidades, ignoradas continuadamente pelos poderes constituídos. Obrigados a encarar a crise e dirimir os efeitos mais perversos das injustiças sociais, os governos e suas políticas não têm conseguido limitar a reprodução das desigualdades, uma vez que, em termos mundiais, a riqueza dos bilionários cresceu $100 \%$ no contexto pandêmico e nos Estados Unidos a pobreza atingiu os mais altos níveis em meio século (Collins, 2020).

No Brasil, especialmente, assistimos estarrecidos ao desmonte de instituições construídas há décadas e tomamos consciência do abismo social que nos caracteriza, patente na classificação de sétimo país mais desigual do mundo, embora ocupe a mesma posição na economia global; a renda média de $1 \%$ dos habitantes mais ricos é $85 \%$ maior em relação aos $50 \%$ mais pobres; $1 \%$ dos mais ricos detêm aproximadamente $1 / 3$ da renda nacional (Neves; Costa, 2020). Nesse momento de crise, exacerbada pela pandemia, os rendimentos dos setores médios e a diminuição das desigualdades ocorrida nas últimas décadas rarefizeram-se. Está em questão o modo como transcorreu a dinâmica de modernização da sociedade brasileira, os efeitos perversos de uma nação cujas classes dominantes foram repetidamente refratárias a enfrentar o problema da desigualdade e a construir projetos socialmente democráticos.

Nessa perspectiva, a sociologia de Florestan Fernandes - que interpretou a constituição da sociedade moderna brasileira no prisma das relações de classes sociais, porém do ângulo daqueles que ocupavam as posições de subordinação (Cohn, 2020, p.1-5) - tornou-se, ainda mais, referência inescapável, por ter enfrentado de forma inequívoca e sem guarida a desigualdade social brasileira, retirando todas as consequências daí advindas no transcurso da modernização. O cruzamento entre classes sociais e discriminação racial, por exemplo, expôs as formas antidemocráticas de exercício do poder, que acabou por modelar os padrões da sociedade brasileira como um todo. Nos seus termos, trata-se de específica realização da revolução burguesa no Brasil, que se cumpriu de forma a não incorporar conquistas civilizatórias, isto é, não afirmou direitos de maneira abrangente, não construiu princípios de cidadania, sequer foi capaz de aderir de fato aos valores da democracia.

A despeito das suas particularidades, a existência da revolução burguesa originou-se da instituição do "regime de classes sociais", vale dizer, da sociedade de classes, mas ignorou os componentes políticos e socioculturais típicos do processo, existentes na sua "vertente clássica". Dessa particularidade, uma sorte de anomalia, quando comparada com exemplares históricos de referência, afirmou-se, responsável pelo caráter autocrático da dominação burguesa no Brasil (Arruda, 2015, p.234-8). As transformações

[...] culminaram em processos de autoafirmação e de autoprivilegiamento das classes e estratos de classes burguesas que em nada contribuíram, positivamente, para a diferenciação e reintegração da ordem competitiva vigente. 
Ao contrário, eles fortaleceram processos que sociólogos como Max Weber considerariam negativos para a consolidação e ulterior desenvolvimento dessa ordem; ou que sociólogos positivistas como Durkheim e especialistas em sociologia aplicada norte-americanos qualificariam de "patológicos" ou “sociopáticos". (Fernandes, 1975, p.356)

Ou, em outros termos, a revolução burguesa no Brasil resultou de relações nas quais a burguesia não foi capaz de conciliar revolução econômica e revolução nacional, contrariamente, aliou-se às oligarquias, num abraço no qual o passado revigorou-se e as forças do progresso arrefeceram seu impulso renovador. Esse enleio do tradicional e do moderno delegou ao Estado funções originariamente atribuídas à burguesia, provocando a perda do seu papel político abrangente, consolidando a relação entre a instituição pública e a classe. "O Estado adquire estruturas e funções capitalistas, avançando através delas, pelo terreno do despotismo político, não para servir aos interesses 'gerais' ou 'reais' da nação, decorrentes da intensificação da revolução nacional” (Fernandes, 1975, p.346). Desse ângulo, a burguesia abdicou do papel que a sua posição social lhe conferia, ao mesmo tempo em que não rompeu com os padrões sociais do passado, foi incapaz de autonomizar-se das oligarquias, vivenciando o drama histórico da sua condição de classe despojada da sua missão, dilema que acompanhou a modernização conservadora brasileira, com todas as consequências daí resultantes.

Para o autor, a revolução burguesa no Brasil consistiu na crise do poder burguês, que se manifesta em recorrentes rupturas democráticas, nas relações privatistas com o poder, nas quais as classes populares estão permanentemente em posição de franca desvantagem, na subserviência em relação às nações hegemônicas, enfim, na manutenção das mais profundas e persistentes desigualdades sociais. Em A revolução burguesa no Brasil, Florestan revelou o processo de "transfiguração histórica da revolução burguesa em modelo autocrático burguês. Uma proeza intelectual ímpar na sociologia brasileira, só possível quando a busca da verdade dos fatos em registro científico vem associada à busca militante de um padrão igualitário e justo nas relações em registro político" (Cohn, 2020, p.3). A irrealização plena da ordem social competitiva, conceito central nas análises de Florestan sobre a constituição do mundo burguês, dado o seu caráter restritivo, privatista e despojado de maleabilidade, uma vez que exclusivamente aquisitivo e que institui, propriamente, o plano da sociabilidade capitalista, estabeleceu as balizas da dinâmica da modernização. No caso do capitalismo dependente, a estruturação do mundo burguês limitou o

[...] florescimento da ordem social competitiva, isto é, de posições sociais e de condutas orientadas segundo os padrões correntes do "capitalismo como estilo de vida"... Nesse universo, precisa-se a revolução burguesa no Brasil, enquanto um modo de combinação singular de formas não homólogas e como um processo que envolve agentes modernizadores, mas cujo raio de ação limita-se a certas esferas da vida social, sem a capacidade de atingir o conjunto da sociedade. (Arruda, 2015, p.234-6) 


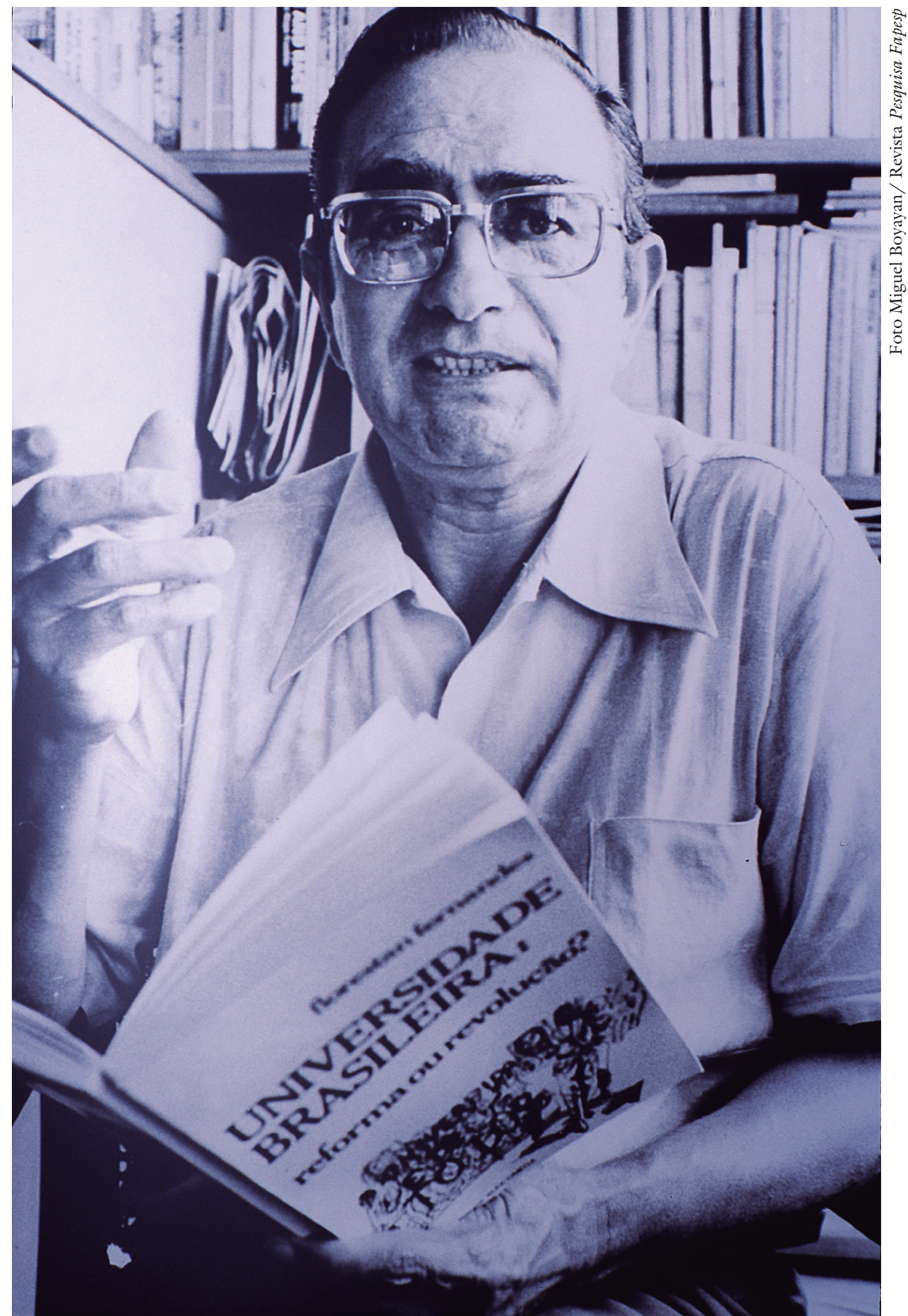

O socióogo Florestan Fernandes (1920-1995). 
Os ganhos obtidos, no passado recente, por camadas sociais no curso da modernização foram parcialmente ou totalmente perdidos, levados de roldão na dinâmica da crise econômica, da crise epidêmica, das reformas políticas neoliberais, no caráter privatizante do Estado. Problemática aguda que está na raiz mesma das desigualdades, das manifestações autocráticas do Estado, que mantém um nexo inelutável na manutenção da hegemonia da classe e o exercício do poder político. Eis o drama da revolução burguesa no Brasil, para cujo entendimento Florestan Fernandes mobilizou toda a sua erudição sociológica na defesa intransigente da crítica, vivendo todas as consequências da sua atuação como intelectual público.

Com efeito, o pensamento de Florestan Fernandes organiza-se a partir de rigorosa análise da formação moderna no Brasil, da revelação dos seus impasses, enfim, da exposição das entranhas de uma sociedade persistentemente desigual, condição escamoteada por concepções avessas a reconhecer as formas mais agudas dos privilégios e perceber quão lesivo para o próprio exercício da dominação é a persistente reprodução desse estado de coisas, que só aprofunda o mal-estar social. Contrariamente, a prática recorrente é a do exercício do poder sem peias, por vezes sem pudor em relação aos requisitos da função pública, como se pode ver nas interrupções da democracia e em situações regressivas, como as atuais. Percebe-se, portanto, a envergadura da contribuição de Florestan Fernandes à elucidação da modernização conservadora no Brasil, bem como das suas modalidades socialmente transtornadas que produziram formas permanentes de marginalização das classes populares. As suas análises sobre as relações raciais e o preconceito de cor são exemplares nesse sentido, pois revelam a conexão entre o destino social dos afrodescendentes no bojo da modernização e do crescimento urbano.

Em $A$ integração do negro na sociedade de classes, sua tese de cátedra publicada em 1965, portanto anterior à A revolução burguesa no Brasil, que surgiu dez anos depois, os problemas fundamentais já estavam formulados. Florestan dirigiu as suas perguntas para explicar os dilemas presentes na constituição da ordem capitalista no Brasil, vividos pelos negros e mulatos, revelando como a condição a que foram relegados exprimia a realização parcial dos requisitos inerentes à ordem moderna. Dito de outro modo, o entendimento dos rumos da revolução burguesa pressupõe tratar a herança escravista no prisma da trajetória dos negros e mulatos, cuja realização mais avançada de constituição do moderno era representada pela cidade de São Paulo. Nesse livro, o arcabouço analítico desenvolvido por Florestan já está formulado, nessa medida, pode ser entendido como origem da sua obra mais alentada sobre a revolução burguesa. De um lado, A integração do negro na sociedade de classes coroa o processo de reflexão sistemática sobre as relações raciais, inaugurado no início da década de 1950 com o projeto Unesco, em busca de entender as raízes da nossa propalada 
democracia racial (Fernandes; Bastide, 1953); de outro, o livro anuncia A revolução burguesa no Brasil, que pode ser interpretado como o fechamento do ciclo (Arruda, 1996b).

Nessa perspectiva, a obra localiza, na passagem da sociedade tradicional para a sociedade de classes, a problemática da marginalização dos afrodescendentes, perquirindo as possibilidades de integração. Já na Nota explicativa, afirma: "Em sentido literal, a análise é um estudo como o povo emerge na história (Fernandes, 2008, I, p.21). ${ }^{3}$ Logo em seguida esclarece:

A escolha de São Paulo como unidade de investigação se explica naturalmente. Ela não só é a comunidade que apresenta um desenvolvimento mais intenso, acelerado e homogêneo quanto à elaboração socioeconômica do regime de classes. É também, a cidade brasileira na qual a revolução burguesa se processou com maior vitalidade, segundo a norma Trabalho-livre na Pátria-livre. Além disso, em virtude de peculiaridades histórico-sociais, nela o "negro" só adquire importância econômica real tardiamente e sofre, em condições sumamente adversas, os efeitos. Assim, o estudo de São Paulo permitia apanhar melhor as conexões existentes entre a revolução burguesa, a desagregação do regime servil e a expulsão do "negro" do sistema de relações de produção. E abria perspectivas únicas para acompanhar as diversas etapas do doloroso drama do "negro", da submersão na miséria e na degradação social até sua lenta revalorização pelo trabalho livre e sua incontida ânsia de "pertencer ao sistema", dignificando-se civil e moralmente. (Fernandes, 2008, I, p.22-3)

Em São Paulo, como "primeiro centro urbano especificamente burguês,... prevalecia uma mentalidade marcadamente mercantil, com seus corolários característicos - o afã do lucro e a ambição do poder pela riqueza. Pensava-se que o 'trabalho livre' e a 'iniciativa individual' e o 'liberalismo econômico' eram os ingredientes do 'progresso', a chave que iria permitir superar o 'atraso do País' propiciar a conquista dos foros de 'nação civilizada' pelo Brasil" (Ibidem, p.34-5). Nesse quadro, a obra analisa as vicissitudes dos negros e mulatos para inserirem-se na nova ordem social, pontuada pelo "estilo de vida individualista e competitivo", construído pelo "novo regime de relações de produção" (ibidem, p.38). Essa é a chave que o permite interpretar a marginalização dos afrodescendentes, o preconceito racial, a mediocridade civilizatória da revolução burguesa, a ausência de democracia, uma vez que a exclusão dos negros é componente integrante do déficit democrático, enfim, por meio do conhecimento do "drama humano do negro", a modernização da nossa sociedade e o próprio Brasil se revelam.

Publicada em dois volumes, o primeiro - O legado da raça branca - abrange o período 1880-1930, tratando da condição de marginalidade dos negros, após a abolição, defrontados com os novos padrões sociais inerentes à sociedade capitalista. Os ex-escravos eram "uma figura deslocada e aberrante no cenário tumultuoso que se forjava graças à "febre do café" (ibidem, p.34). A rápida 
transformação da cidade de São Paulo, ocorrida entre o fim do século XIX e começo do século XX, impossibilitou a inserção dos negros ao estilo urbano de vida. Deixados à própria sorte, os egressos do cativeiro não seriam capazes de mobilizar as novas regras sociais, condição indispensável na sua transformação em trabalhadores livres. Deslocados da seara da competição por ocupações, os negros não conseguiram enfrentar os imigrantes, por estarem infensos às normas intrínsecas da sociedade em emergência. Marcados pela pauperização e desorganização "viveram dentro da cidade, mas não progrediram com ela e através dela. Constituíam-se numa congérie social, dispersa pelos bairros, e só partilhavam em comum uma existência árdua, obscura e muitas vezes deletéria. Nessa situação, agravou-se, em lugar de corrigir-se, o estado de anomia social transplantado do cativeiro" (ibidem, p.120). Em outros termos, a heteronomia da "situação de castas" impediu aos negros assimilarem as potencialidades presentes numa "situação de classes".

A cidade de São Paulo com o ritmo intenso de urbanização, cenário do desajustamento estrutural dos negros, ofereceu o quadro morfológico da pesquisa. A resolução do drama dos negros exigia medidas de reintegração após a extinção da escravatura, o que teria permitido o aparecimento de formas de ajustamento ao regime da produção capitalista nas suas expressões econômica, social e política. A exclusão dos negros e mulatos desse processo corroeu os fundamentos jurídicos e morais das relações contratuais, "projetando-os no seio da plebe sem livrá-los dos efeitos diretos ou indiretos dessa classificação. Em plena fase de consolidação da ordem social competitiva e do regime de classes, a 'população de cor' subsiste numa posição ambígua, representada, confusamente, como se constituísse num estamento equivalente ocupado pelos 'libertos' na velha estrutura social" (ibidem, p.303). O centro dinâmico da sociedade em formação girará em torno das personagens centrais do fazendeiro e do imigrante, aguçando as dificuldades de ajustamento dos negros, vedando-lhes o acesso aos princípios da socialização emergente. Na base de tal processo, encontram-se o "desajustamento estrutural” e a "desorganização social” típicos da condição de negros e mulatos, pois não aconteceu a reclassificação social. A vivência dos estados de anomia e heteronomia, por parte desse contingente de marginalizados, diluiu a construção da nova identidade que, em última instância, sequer se forma, tendo em vista que a não inserção na ordem social competitiva, também não lhes facultava a possibilidade de atuarem solidariamente às classes trabalhadoras em formação. Não por casualidade, em obra posterior, mas a partir das pesquisas realizadas na década de 1950, Florestan enfatiza tanto as dimensões da cultura negra, quanto o enleio entre a condição dos afrodescendentes e as classes trabalhadoras (Florestan, 1989). Relegados após a escravidão, produziram, no momento seguinte, situação aberrante nos quadros da nova sociedade, por perpetuarem princípios passadistas de formação das posições e papéis sociais. "O regime extinto não desapareceu por completo após a abolição. Persistiu na mentalidade, no comportamento e até na organização das relações sociais dos 
homens, mesmo daqueles que deveriam estar interessados numa subversão total do antigo regime" (Fernandes, 2008, I, p.302).

Explicita-se, nessas passagens, determinada compreensão da história brasileira, cujo ritmo de transformação não se fez pela eliminação dos ditames da velha sociedade, ao contrário, mesclaram-se à nova dinâmica. A convivência de tempos diversos

[...] indica claramente que a ordem social e a ordem racial da sociedade inclusiva se transformavam com intensidade bem desiguais [...] Como se o modelo da organização de castas ainda imperasse, o setor constituído pelo estoque racial "branco" engrenava-se nos fluxos das transformações históricas da ordem social, enquanto o estoque racial "negro" permanecia estagnado e as inter-relações dos dois continuavam a ser reguladas pelos velhos padrões. Proscrito da história e da participação das pugnas sociais que decidiam do seu curso, o "homem de cor" estava bloqueado em uma zona estagnada e estática da sociedade. Por isso, em contraste com a alteração tumultuosa do cenário histórico-social, a ordem racial tendia a manter-se em estado estacionário. (Fernandes, 2008, p.321)

A esse fenômeno de demora cultural, de persistência de relações arcaicas, corresponde à identidade negra não constituída e à captura da sua condição de sujeitos.

Desse ângulo, as debilidades históricas, que cercaram a formação e o desenvolvimento inicial do regime de classes, contam como muito mais decisivas para a preservação de grande parte da antiga ordem racial, que as predisposições do "branco" de precaver-se do "negro livre". Pura e simplesmente, aquele não se defrontou com semelhante alternativa histórica, como aconteceu, por exemplo, em situação análoga nos Estados Unidos. (ibidem, p.305)

A contraface da ausência de lugar do negro na nova ordem reside no denominado mito da democracia racial, analisado no último capítulo do primeiro volume, no qual o sociólogo desmonta a crença numa sociedade racialmente aberta. Caracterizando a construção racial imperante no Brasil como consciência falsa, o autor revelou a funcionalidade desse mito na manutenção dos padrões sociais herdados da escravidão que, não obstante, impõem limites à realização da ordem social competitiva. Nos seus termos, "por paradoxal que pareça, foi a omissão do ‘branco' - e não a ação - que redundou na perpetuação do status quo ante... o campo ficou aberto para a sobrevivência maciça de padrões de comportamento social variavelmente arcaicos" (ibidem, p.305). Dito de outro modo, a crença na democracia racial produziu uma inércia social que justificava a desigualdade e o preconceito: para os brancos uma espécie de "boa consciência" reconciliada consigo própria; para os negros formas diferenciadas de acomodação.

No quadro dessas considerações, explicitam-se concepções do autor: o conceito de ordem social competitiva, ou de sociedade capitalista, enquanto forma de estratificação aberta e tendencialmente democrática; a identificação do mito à ideologia, numa acepção mais restrita a esse fenômeno de natureza 
simbólica. Nesse sentido, Florestan trabalha com a noção de mito no sentido diverso da tradição antropológica, ou seja, enquanto universo de representações exclusivas. De outro lado, a discussão do mito da democracia racial permite-lhe ultrapassar certas visões dominantes e "representa uma recusa à visão conservadora que marca o debate não somente sobre a questão racial, mas também na Sociologia no Brasil" (Bastos, 1987, p.141). No interior desses parâmetros analíticos, o sociólogo desenvolveu a segunda parte da sua reflexão, quando a ordem social competitiva se expandiu no sentido capitalista, no momento da segunda revolução industrial, o que possibilitou o reequacionamento das formas de integração do negro.

O segundo volume - No limiar de uma nova era - perscruta, por intermédio dos movimentos negros, as condições de possibilidade de transformação das relações raciais herdadas do antigo regime, a partir de 1930. O entrecruzamento entre cor e estratificação socioeconômica, ao pautar o desenvolvimento da análise, leva o autor a pensar as modalidades de inserção dos negros e mulatos que começam a ocorrer de modo paulatino, através da distribuição das ocupações. Trata-se de compreender como as relações raciais, pervertidas e assimiladas pelos padrões tradicionalistas, adquirem, cada vez mais, nova feição por intermédio da ação dos movimentos oriundos do meio negro. Um processo social que, embora tímido, representava formas de reação ao modus-vivendi. No passado, “o 'negro' vivia numa sociedade organizada em classes sem participar do regime de classes. O termo 'preto' permitia selecionar a cor como marca racial para distinguir, a um só tempo, um estoque racial e uma categoria social em situação societária ambígua, para não dizer francamente marginal" (Fernandes, 2008, I, p.339). Em outros termos, impunha-se acompanhar os desdobramentos dos dois grandes dilemas sociais, vividos pelos negros, no período anterior.

Primeiro, havia o dilema da absorção da "população de cor" às formas de vida social organizadas imperantes na ordem social competitiva [...] Segundo, havia o dilema do "preconceito de cor", ou seja, no que isso significa na sociedade brasileira, da perduração da velha associação entre cor e posiç̧ão social infima, a qual excluía o "negro", de modo parcial ou total (conforme os comportamentos e os direitos sociais considerados) da condição de gente. (Fernandes, 2008, v.II, p.7)

O protesto negro, muito embora não fosse suficientemente forte para superar as desigualdades raciais, explicita a construção de uma nova era histórica, na qual os herdeiros do cativeiro começam a afirmar-se como homens livres e cidadãos, porém mantém-se o desequilíbrio entre ordem social e sistema racial dominante. As formas de ajustamento social, ao se individualizarem, não eram propícias à superação do preconceito, expressão, por sua vez, de afastamento dos princípios de uma sociedade aberta, ou seja, socialmente plástica.

O prestígio e o poder que são apanágios dos dominantes permanecem enleados aos princípios sociais herdados do passado e encarcerados pela ordem racial branca, que não foi negada quando da ascensão dos imigrantes. No que 
tange à condição social dos negros, a lentidão e descontinuidades do ritmo da integração apontam para os dilemas de uma história que não rompeu integralmente com as cadeias do passado, retirando dos afrodescendentes a possibilidade de constituírem-se, efetivamente, em sujeitos da sua trajetória social. Essa via de ligação entre o passado, o legado cultural da sociedade escravista e o presente transmudou-se ao longo do tempo, sem ultrapassar a herança da escravidão. As injunções da história pregressa, se não foram gestadas na dinâmica intrínseca à ordem social competitiva, exprimiram a tenacidade do modelo tradicional de relação racial. Nesse contexto, "a formação e a consolidação do regime de classes não seguiram um caminho que beneficiasse a reabsorção gradual do ex-agente do trabalho escravo. A ordem social competitiva emergiu e se expandiu, compactamente, como um autêntico e fechado mundo dos brancos" (Fernandes, 2008, v.II, p.568). Se as manifestações ostensivas do preconceito são afastadas, no andamento da crise da visão tradicionalista, não se desvenda a realidade das relações raciais e o preconceito de não ter preconceito, expressão cunhada por Florestan Fernandes, véu que encobre a visão dos que não querem perceber, daqueles que ignoram, pois imaginam que o problema reside em controlar a discriminação por ser um dever humanitário. O preconceito de não ter preconceito particulariza as expressões de alheamento do branco em relação ao drama do negro e revela a especificidade da discriminação no Brasil, cujo reconhecimento rompe a construção mítica da democracia racial.

No andamento dessa análise, Florestan Fernandes construiu o problema crucial do livro, presente no modo como relacionou a condição do negro na formação e expansão da sociedade de classes. A persistência do padrão de relações étnicas do passado impediu a que a ordem social competitiva pudesse promover outras formas de ajustamento racial, criando obstáculos à realização plena da nova moralidade social. Em suma, não se construiu no Brasil uma ordem burguesa aberta e democrática, como ocorreu em outros países, mas uma ordem burguesa enrijecida e autocrática. Desse ponto de vista, afirma-se a relação entre a marginalidade dos negros e instituições democráticas débeis; reversivamente, a ultrapassagem da condição dos negros é requisito da ordem democrática. Na gênese da sociedade de classes no Brasil imiscuíram-se os traços do passado, dificultando a plena constituição da ordem social competitiva. O drama racial brasileiro está no próprio cerne dos descaminhos da nossa história moderna. Em outros termos, na história da formação da ordem social competitiva estabeleceram-se descontinuidades, uma junção de elementos em si mesmos distintos, responsáveis pela criação de uma síntese de contrários. No interior dessa realidade contraditória, o encaminhamento da questão do negro é decisivo para fundamentar uma sociedade moderna e democrática.

E aqui delineia-se a importância de $A$ integração do negro na sociedade de classes no universo das reflexões de Florestan Fernandes sobre o Brasil. Enquanto nessa obra o autor localiza as dificuldades para a realização dos princípios da ordem social competitiva e que envolvem a existência de uma estrutura de 
classes aberta e tendencialmente democrática, em livros posteriores, sobretudo em $A$ revolução burguesa no Brasil, o diagnóstico é diverso. Ou seja, acentua-se a presença dessa identidade problemática, de difícil enquadramento, restritiva quanto à efetivação dos processos sociais típicos. Se em $A$ integração do negro, apesar do diagnóstico a respeito, o sociólogo advertia sobre a necessidade de "introduzir serviços especiais, de âmbito nacional, regional e local, para lidar com os problemas práticos de absorção de contingentes populacionais diversos a uma sociedade democrática" (ibidem, v.II, p.575), as obras posteriores expressam franca descrença.

Nesse contexto, o dilema racial brasileiro representa o próprio dilema da formação da moderna sociedade no Brasil, fruto do drama de uma história singular, por não desenvolver as possibilidades mais avançadas contidas na dinâmica da sua transformação. E o avanço identifica-se com as formas democráticas e de oportunidades igualitárias, configurando uma análise lastreada na perspectiva das classes populares. Em A integração do negro, o sociólogo assinalou o seu "constante esforço de projeção endopática na situação humana do negro e do mulato", mas alertou que procurou "evitar, cuidadosamente, que esse estado de espírito interferisse nas interpretações" (Fernandes, 2008, v.I, p.26). Em texto posterior, após 25 anos e realizando um balanço do livro, ponderou: "aceitávamos, abertamente, uma identificação moral e política com o negro, como condição intelectual para que nossa contribuição se inserisse no processo de criação de uma verdadeira democracia racial - mas por mais que pretendêssemos nos superar, tivemos que cair nas malhas do conhecimento científico, circunscrito e especializado" (ibidem, p.101). A nuança encerrada nos dois depoimentos, se exprime o percurso da sua reflexão, revela os princípios que distinguiram a trajetória de Florestan Fernandes e explica a profusão de estudos sobre a sua obra e trajetória.

\section{III}

Os estudos de Florestan Fernandes sobre as relações raciais expuseram a raiz do chamado racismo estrutural, uma vez que explicam os fundamentos do preconceito e, no caso brasileiro, a sua relação intrínseca com a estratificação de classes, as formas arrevesadas da modernização brasileira, o caráter privatista da ordem social competitiva, a estrutura autocrática de exercício do poder, que resultaram na profundidade da desigualdade social do Brasil. Nesse sentido, a obra de Florestan revela inequívoca atualidade. Apesar disso - que já seriam motivos sobejos de retorno aos escritos desse que foi o mais destacado sociólogo brasileiro -, Florestan foi um intelectual público de cariz excepcional. Além de ter empunhado bandeiras civilizatórias, como a da Campanha na defesa da escola pública (Fernandes, 1966), mesmo após o seu afastamento compulsório da universidade, no retorno do exterior, não deixou de atuar contra todas as manifestações antidemocráticas, tampouco ignorou compromissos político-partidários, tendo sido eleito deputado do Partido dos Trabalhadores (PT) e atuado ativamente na Assembleia Constituinte na defesa de bandeiras democráticas. 
Por todos esses motivos, Florestan ocupou o lugar do intelectual público, daquele defensor das causas mais genuínas e que se lastreavam no domínio do conhecimento. Nesse diapasão, o sociólogo serviu de modelo para os intelectuais da universidade, hoje muito acanhados na cena pública, mesmo porque as nossas instituições se transformaram, sobretudo, em organismos administrativos, limitados por compromissos, muitas vezes externos aos nossos muros. A sua adesão à ciência se realizou em uma conjuntura na qual os intelectuais eram instados a se tornarem atores políticos. Interessante recuperar as suas palavras:

O problema é da objetividade: o conhecimento precisa ser um conhecimento verificável, objetivo, que outros investigadores possam controlar. Neutralidade no sentido da indiferença, do cada um que faça o que achar melhor isso já seria admitir que o intelectual vai além do mandarim, livre para desfrutar todos os benefícios sem precisar dizer à sociedade a que vem. Em suma, ele teria o privilégio de fazer parte de um jogo cujas regras ele próprio determinaria e que excluiria da comunhão com os outros seres humanos. Responsáveis da mesma sociedade. [...] De fato, nenhum intelectual é neutro. [...] Portanto, a suposta neutralidade não é neutra, pois ela envolve a utilização do intelectual nos piores fins... (Florestan, 2020, p.81-2)

No momento no qual o intelectual acadêmico perdeu a sua aura, submetido a regras internas e externas à instituição, reler Florestan Fernandes não deixa de ser uma maneira de repensar o sentido da nossa atividade. Talvez resida, exatamente aí, um dos motivos da atração por ele exercida.

\section{Notas}

l A obra de Florestan Fernandes está sendo reeditada pela editora Contracorrente, sob a coordenação do cientista social Bernardo Ricupero. Em 2005, a editora Globo republicou, sob minha coordenação, a maior parte dos seus livros.

2 Utilizo-me da primeira edição de A revolução burguesa no Brasil, de 1975.

3 A primeira publicação em editora comercial da obra é de 1965. Utilizo-me da edição de 2008.

\section{Referências}

ARRUDA, M. A. do N. A imagem do negro na obra de Florestan Fernandes. In: SCHWACZ, L.; QUEIROZ, R. da S. (Org.) Raça e diversidade. São Paulo: Edusp, 1996a.

. Dilemas do Brasil moderno: a questão racial na obra de Florestan Fernandes. In: MAIO, M. C.; VENTURA, R. (Org.) Raça ciência e sociedade. Rio de Janeiro: Fiocruz, 1996b.

Prefácio. Uma sociologia do desterro intelectual. In: FERNANDES, F. Circuito fechado. São Paulo: Globo, 2005.

Metrópole e cultura. São Paulo no meio século XX. São Paulo: Edusp,

2015. 
ARRUDA, M. A. do N. El concepto de formación en tiempos críticos: esbozo de reflexión. Sociológica (Méx.) v.32, n.90, p.47-6, 2017.

. The contemporary relevance of Florestan Fernandes. Antropol. [online]. v.8, n.1, p.47-68, jan-abr. 2018.

. Florestan Fernandes e a sociologia da consciência social. Margem Esquerda, n.34., jun. 2020 .

ARRUDA, M. A. do N.; GARCIA, S. G. Florestan Fernandes. Mestre da sociologia moderna. Brasília: Paralelo 15, 2003.

BASTOS, E. R.; BOTELHO, A. A questão racial e a revolução burguesa. In: D'INCAO, M. A. (Org.) O saber militante. Ensaios sobre Florestan Fernandes. São Paulo: Paz e Terra; Unesp, 1987.

. Horizontes das ciências sociais: pensamento brasileiro. In: MARTINS, C. B.; MARTINS, H. T. S. (Org.). Horizontes das ciências sociais no Brasil: sociologia. São Paulo: Anpocs, 2010.

BOTELHO, A.; BRASIL JUNIOR, A. Prefácio. A revolução burguesa no Brasil: cosmopolitismo sociológico e autocracia burguesa. In: FERNANDES, F. A revolução burguesa no Brasil. Ensaio de interpretação sociológica. 6.ed. São Paulo: Contracorrente, 2020.

BOUSHEY H.; BRADEFORD DELONG, J.; STEINBAUM, M. After Piketty. The agenda for econômicas and inequality. Cambridge MA; London: Harvard University Press, 2017.

COHN, G. Ecletismo bem temperado. In: D’INCAO. M. A. (org). O Saber militante: ensaios sobre Florestan Fernandes. São Paulo: Editora UNESP/Paz e Terra, 1987.

. A revolução burguesa no Brasil. In: MOTA, L. D. (org). Introdução ao Brasil: um banquete no trópico. São Paulo: SENAC, 1999.

. A revolução burguesa no Brasil. Disponível em: <https://aterraeredonda. com.br>. Acesso em: 26 set. 2020.

COLLINS, C. Disponível em: <www.cnnbrasil.com.br>. Acesso em: 1 maio 2020.

FERNANDES, F. Educação e sociedade. Dominus/Edusp, São Paulo, 1966.

A revolução burguesa no Brasil. Ensaio de interpretação sociológica. Rio de Janeiro: Zahar, 1975.

. O significado do protesto negro. São Paulo: Cortez, São Paulo: 1989.

. Circuito fechado. Quatro ensaios sobre o "poder institucional”. São Paulo:

Globo, 2005.

A integração do negro na sociedade de classes. São Paulo: Globo, 2008. 2v.

. Entrevista. GALVÃO, W. N. (Org.) Sobve os primórdios da Faculdade de

Filosofia, Letras e Ciências Humanas da USP. São Paulo: Edusp, 2020.

FERNANDES, F.; BASTIDE, R. Brancos e negros em São Paulo. São Paulo: Cia. Editora Nacional, 1953.

JACKSON, L. C.; BLANCO, A. Sociologia no espelho. Ensaístas, cientistas sociais e críticos literários no Brasil e na Argentina (1930-1970). São Paulo: Editora 34, 2014. 
JACKSON, L. C.; BLANCO, A. Vida e história na sociologia de Florestan Fernandes: reflexões sobre o método da história de vida. Revista USP, n.29 mar-mai. 1996.

MARTINS, J. de S. Florestan: sociologia e consciência social no Brasil. São Paulo: Edusp, 1998.

NEVES, E.; COSTA, M. Disponível em: <Veja.abril.com.br>. Acesso em: 20 jul. 2020.

PIKETTY, T. Capital in the twenty-first century. Cambridge Ma; London, 2014. The economics of inequality. Cambridge Ma; London, 2015.

RESUMO - O objetivo do artigo é analisar a contribuição sociológica de Florestan Fernandes, sob variadas perspectivas: entender os motivos que explicam a vasta fortuna crítica existente sobre sua obra e trajetória; o escopo analítico das suas reflexões sobre a constituição da revolução burguesa no Brasil; as conexões entre relações raciais, preconceito e a estruturação da modernização brasileira. Finalmente, estabelece inferências entre os estudos sobre a trajetória e a obra do sociólogo maior do Brasil e os problemas do tempo presente, pondo em relevo o papel dos intelectuais.

PALAVRAS-CHAVE: Florestan Fernandes, Sociologia, Revolução burguesa, Relações raciais, Sociedade moderna no Brasil.

ABSTRACT - The aim of the article is to analyze the sociological contribution of Florestan Fernandes from different perspectives: understanding the reasons that explain the vast critical fortune that exists on his work and trajectory; the analytical scope of his reflections on the constitution of the bourgeois revolution in Brazil; and the connections between race relations, prejudice, and the structuring of Brazilian modernization. Finally, this essay draws inferences between the studies about the trajectory and work of Brazil's greatest sociologist and the problems of the present time, highlighting the role of intellectuals.

KEYWORDS: Florestan Fernandes, Sociology, Bourgeois revolution, Race relations, Modern society in Brazil.

Maria Arminda do Nascimento Arruda é professora titular do Departamento de Sociologia, da Faculdade de Filosofia, Letras e Ciências Humanas da USP.

@ - arr@usp.br / https://orcid.org/0000-0002-1609-6743.

Recebido em 2.10.2020 e aceito em 7.10.2020.

I Faculdade de Filosofia, Letras e Ciências Humanas, Universidade de São Paulo, São Paulo, Brasil. 
